\title{
A BANALIZAÇÃO DA SUSTENTABILIDADE: reflexões sobre governança ambiental em escala local
}

Igor Ferraz da Fonseca*

Marcel Bursztyn**

Resumo: O processo decisório e de implementação de políticas ambientais tende a adotar práticas que obedecem a critérios que se consagram internacionalmente como condições de possibilidade e de suficiência para que os fins desejados sejam atingidos. É como se existisse uma cartilha que estabelecesse as regras gerais da busca do desenvolvimento sustentável. Na atualidade, uma espécie de manual (virtual) da boa governança serve de guia e pré-requisito na elaboração de programas e projetos socioambientais. Porém, a reprodução indiscriminada e a ampliação interminável, ao longo do tempo, da lista de quesitos considerados como ingredientes necessários, podem ter efeito contrário ao esperado e constituir obstáculo para que as políticas ambientais e de desenvolvimento sejam eficientes. A preocupação em cumprir formalmente com critérios gerais pode obscurecer a sua expressão substantiva. Com isso, há espaço para "caronas” do discurso ambientalista e para um fosso entre o discurso e a prática na gestão ambiental. O objetivo deste estudo é demonstrar como os quesitos considerados necessários para uma boa governança são produzidos e reproduzidos ao longo do tempo. Esta dinâmica, sob a égide do manual, favorece a banalização e a volatilidade dos quesitos mencionados. Ao banalizar a sustentabilidade, amplia-se cada vez mais a distância entre o discurso politicamente correto e a eficácia prática de políticas ambientais e de desenvolvimento. Para reduzir essa distância, é proposta a utilização do conceito de governança suficientemente

\footnotetext{
* Sociólogo, mestrando do Centro de Desenvolvimento Sustentável da Universidade de Brasília (UnB).E-mail: igorfonseca@ibest.com.br

** Economista e sociólogo, professor do Centro de Desenvolvimento Sustentável da UnB. E-mail: marcel.cds@gmail.com
}

Artigo recebido em 25 out. 2008 e aprovado em 22 jan. 2009. 
boa. Esse conceito pode representar uma alternativa às falhas do manual, ao focar aspectos essenciais, separando o desejado do possível e do indispensável.

Palavras-chave: boa governança; governança ambiental; free-rider; participação; capital social; descentralização; empoderamento.

\section{Introdução}

Governança é um termo-chave na implementação de políticas ambientais e de desenvolvimento. Uma boa governança seria capaz de aumentar a eficiência e a legitimidade na elaboração e na operação dessas políticas. Porém, muitos projetos calcados na tentativa de instituir e se valer de condições ideais de governança têm apresentado impasses estruturais. Por outro lado, mesmo diante de evidentes limitações, os critérios considerados necessários para a boa governança se multiplicam. Essa dinâmica, que amplia o fosso entre o discurso e a prática no tratamento da questão ambiental, vem se reproduzindo e ampliando ao longo do tempo.

Este artigo explora a produção e a reprodução dos critérios apontados pelos tomadores de decisão e articuladores de movimentos sociais como elementos essenciais à promoção de projetos relacionados ao desenvolvimento socioambiental na esfera local. A esse conjunto de critérios chamamos aqui de Manual da Boa Governança (MBG). Sustentamos que a lógica dos freeriders discursivos - ou caronas do discurso - permeia o processo de implementação de políticas ambientais e constitui elemento que ajuda a explicar a existência de tal fosso.

Vale ressaltar que o MBG não é um documento formal, uma cartilha. A expressão é usada para representar o referencial geral de princípios e critérios que servem de pano de fundo ao estabelecimento de políticas e de projetos ambientais, independentemente do contexto específico das realidades onde os mesmos de aplicam. No processo 
de produção e reprodução das políticas e de projetos, alguns quesitos são vistos como fundamentais para o que se entende como boa governança e são rapidamente assimilados e disseminados. O MBG, como um tipo ideal weberiano, é um construto teórico que abarca tais quesitos e permite o entendimento das potencialidades e limitações da adoção, de forma indiscriminada, de fórmulas idealizadas como essenciais para uma governança desejável.

O objetivo deste estudo é demonstrar como os quesitos considerados necessários para uma boa governança são produzidos e reproduzidos ao longo do tempo. Esta dinâmica, sob a égide do MBG, favorece a banalização e a volatilidade dos quesitos mencionados. Ao banalizar a sustentabilidade, amplia-se cada vez mais a distância entre o discurso politicamente correto e a eficácia prática de políticas ambientais e de desenvolvimento.

A segunda parte do texto apresenta o conceito de governança, focando os seus usos nos processos de decisão e implementação de políticas ambientais e de projetos focados no desenvolvimento sustentável ao nível das comunidades. Aborda, também, a existência, na prática, de MBGs constituídos de um amplo número de critérios considerados necessários para a eficácia das políticas ambientais. Em seguida, a terceira seção discute o contexto de produção e reprodução de MBGs. A quarta seção foca algumas limitações que os MBGs apresentam em sua aplicação prática. A seção seguinte explicita a regra dos free-riders discursivos, que são aqueles que reproduzem MBGs sem precisar segui-los na prática, o que amplia a distância entre o discurso e a realidade nas políticas ambientais. Na sexta seção, é apresentado o conceito de governança suficientemente boa, que pode ser uma alternativa para mitigar as limitações estruturais do MBG.

As considerações finais deste estudo apontam para a necessidade de se relativizar a implementação dos critérios 
considerados necessários para a boa governança, estabelecendo uma hierarquia no tempo e entre prioridades no que concerne aos critérios mencionados. Sendo assim, a replicação de projetos e programas ambientais e de desenvolvimento deve ser pautada pelas especificidades dos contextos particulares, pois são essas especificidades que determinam o sucesso ou fracasso do projeto ou programa implementado.

\section{O conceito de governança e o Manual da Boa Governança}

O fortalecimento da governança representa uma possibilidade de estabelecer um processo político mais abrangente, eficiente e justo. A idéia de governança promove o pluralismo político (McFarland, 2007), a eficiência e a transparência nas escolhas e decisões públicas, visando incluir uma ampla gama de atores sociais e processos.

Para Grindle (2004), governança consiste em: distribuição de poder entre instituições de governo; a legitimidade e autoridade dessas instituições; as regras e normas que determinam quem detém poder e como são tomadas as decisões sobre o exercício da autoridade; relações de responsabilização entre representantes, cidadãos e agências do Estado; habilidade do governo em fazer políticas, gerir os assuntos administrativos e fiscais do Estado, e prover bens e serviços; e impacto das instituições e políticas sobre o bem-estar público. Quando o conceito de governança é estendido à esfera do desenvolvimento sustentável e das políticas ambientais, emprega-se a expressão governança ambiental. Trata-se, na verdade, apenas de uma delimitação temática do conceito.

O processo de governança envolve múltiplas categorias de atores, instituições, inter-relações e temas, cada um dos quais suscetível a expressar arranjos específicos entre interesses em jogo e possibilidades de negociação. Nesse sentido, a noção de 
governança pública deve ser diferenciada da privada e expressar questões de interesse de coletividades, nas quais deve prevalecer o bem comum.

A emergência do conceito está ligada a um amplo processo de redução do Estado e à valorização da incorporação de atores externos ao aparato estatal no processo político e na gestão de políticas públicas. Isso está relacionado à disseminação de idéias e de práticas neoliberais, no último quarto do século passado, mas a sua trajetória ganhou vida própria e adquiriu características que vão muito além da mera transferência da responsabilidade regulatória do governo para o mercado. Atributos como participação, descentralização, responsabilização e equidade entre os atores dão à noção de governança um conteúdo de legitimidade e pragmatismo, abrindo espaço para uma regulação que leve em conta fatores extraeconômicos.

Coincidindo com o período de disseminação das práticas do neoliberalismo e como resposta ao relativo fracasso das políticas de desenvolvimento dos anos 1980, o conceito de governança foi adotado por agências internacionais de desenvolvimento, como o Banco Mundial e o Fundo Monetário Internacional, e passou a ser um elemento-chave da agenda de implantação de projetos de diversas naturezas, em países pobres. Nesse contexto, os organismos internacionais de financiamento do desenvolvimento definem diversos componentes que consideram como ingredientes necessários para uma boa governança, num processo que tem muito de tentativas, erros e acertos, ou seja, de aprender fazendo.

Critérios que, de alguma forma, são entendidos como suscetíveis de contribuir para o aprimoramento do processo político, são adotados e listados em check-lists de aspectos considerados essenciais aos programas e projetos. É isso que chamamos aqui de Manual da Boa Governança (MBG). A observância desse manual deve ser buscada pelo atendimento de pré-requisitos estruturais, 
independentemente do contexto onde se dá o processo político (Harriss, 2001, Fine, 1999, Bebbington, 2007). O conteúdo geral do MBG é continuamente ampliado e hoje contém uma ampla lista, que pode atingir mais de 200 itens (Grindle, 2004).

Como exemplo de critérios do MBG, o Banco Mundial e o Fundo Monetário Internacional analisam e selecionam os projetos que financiam com base em uma lista de condicionalidades que devem ser atendidas (Nanda, 2006, Drake et al., 2002, Santiso, 2001). Santiso (2001) demonstra que, ainda no ano de 1999, os projetos e programas financiados por essas duas organizações deveriam atender a uma extensa lista de condições ligadas à governança, como é o caso de Senegal (99 condições), Quirguistão (97), Indonésia (81), Mali (67), Camboja (65), Brasil (45), entre outros. Conceitos e critérios como empowerment (empoderamento), participação, capital social, accountability (responsabilização), descentralização, educação de qualidade, combate à corrupção, eficiência dos mercados, mãode-obra qualificada, igualdade de gênero, respeito à propriedade e à livre iniciativa, distribuição equitativa de renda, entre outros, comparecem em uma agenda cada vez mais ampla e repleta de boas intenções. A sua praticidade, entretanto, é limitada justamente pelo fato de ser genérica, muito abrangente e, com freqüência, distante das realidades específicas nas quais se tenta implementá-la.

\section{A produção e reprodução do Manual de Boa Governança}

Um efeito paralelo à disseminação da agenda neoliberal foi o maior ativismo de alguns setores da sociedade civil organizada. No vácuo deixado pela redução (e mesmo inexistência) da ação reguladora do Estado, paralelamente ao crescimento das forças de mercado no processo de regulação pública, as organizações nãogovernamentais passam a ser importantes atores na definição e gestão de políticas públicas. Essas organizações, cuja ação é focalizada em 
certos segmentos da sociedade, tendem a buscar recursos em órgãos de governo ou organismos internacionais.

Nessa relação, tende a ocorrer um duplo efeito: por um lado, percepções sobre características de comunidades locais são transmitidas às agências financiadoras, que podem incorporá-las em suas agendas; por outro lado, tais agendas passam a constituir critérios de essencialidades, como o MBG. Nesse contexto, surgem espaços para a expressão de problemas, pois a reprodução das chamadas boas práticas nem sempre encontra realidades semelhantes às que lhes serviram de referência, podendo resultar em frustrações ou mesmo na imposição de condutas e critérios equivocados, de cima para baixo. Geralmente, os componentes incluídos no $\mathrm{MBG}$ refletem casos particulares de nações, regiões ou localidades em que se verificou algo novo e de sucesso. No entendimento geral (e simplificador), as boas práticas devem ser disseminadas e reproduzidas, entendendo-se isso como uma garantia de boa governança. Entretanto, paradoxalmente, a razão do sucesso tende a ser justamente o fator originalidade dessas práticas.

Como resultado desse processo, o Manual da Boa Governança é consolidado ao mesmo tempo em que vai sendo ampliado e tornase base das políticas ambientais e de desenvolvimento. Esse mesmo processo, por outro lado, faz com que o manual seja crescentemente descontextualizado, acrítico, ingênuo e pouco útil como ferramenta prática para o aprimoramento das políticas. Nesse sentido, o ideal de boas práticas tende a levar a frustrações, quando transposto para realidades diferentes, resultando em más práticas.

As chances de um programa ou projeto ser aprovado por agências financiadoras aumentam, à medida que eles expressem a sua adesão, ao menos formalmente, aos critérios do MBG. Quanto maior o número de elementos da lista de quesitos da boa governança o projeto contiver, maiores as suas chances de ser aprovado e 
financiado, pois “os doadores e instituições financeiras internacionais estão cada vez mais baseando a sua ajuda e os seus empréstimos com a condição de que sejam promovidas reformas que assegurem a boa governança” (Unescap, 2009, tradução dos autores).

No meio acadêmico, também, há amplo espaço para disseminação do MBG. Isso se deve a vários fatores, como a tendência de adesão a idéias mainstream, muito comum nas universidades, ou a proximidade entre profissionais atuantes nas agências de financiamento e o mundo acadêmico (Bebbington, 2004). Enquanto as agências financiadoras são os atores principais na consolidação do MBG, o meio acadêmico tem papel proeminente em sua ampliação, que decorre do próprio debate sobre o tema. Dito de outra forma, na interação entre burocracia, prática e academia, o mundo universitário tende a contribuir para a tradução teóricoconceitual das experiências reais, lapidando idéias e produzindo conceitos que se tornam novos itens do MBG.

\section{As falhas da boa governança}

A despeito das boas intenções inerentes à definição de boa governança, o processo político moderno é complexo e demanda soluções específicas. Situado em uma ampla arena que envolve princípios, valores e interesses distintos, trata-se de um jogo no qual alianças e oposições são constantemente definidas e redesenhadas. A tentativa de inclusão de múltiplos atores na gestão pública é necessária, mas uma enorme gama de fatores age sobre o processo e deve ser considerada.

O MBG - por ser um conjunto de critérios gerais -, não dá a devida importância a essa complexidade, que tem expressões particulares em cada situação. A sua implementação é baseada em elementos pré-determinados e na busca de replicação de programas 
e projetos avaliados como experiências de sucesso nos contextos em que foram originalmente implantados. O problema principal do MBG é que replicar ações com vistas a criar elementos que foram bem sucedidos em determinadas realidades não garante que os resultados sejam os mesmos em outros contextos. Com efeito, dificilmente os resultados desta reprodução atingem o mesmo grau de eficiência alcançada nos contextos originais. Isso ocorre porque cada situação particular tem características culturais, econômicas, ambientais, políticas e sociais diferenciadas, o que faz com que a fórmula buscada com a replicação impacte distintamente o meio no qual é inserida, visto que a realidade-alvo condiciona, modifica e pode até distorcer o eixo da intervenção.

A descentralização, como um princípio integrante do MBG, é exemplo que ajuda a explicar esta tendência. Descentralizar a elaboração e a implementação de políticas públicas tem como objetivo tornar o processo mais eficiente, ágil e democrático. Contudo, em alguns contextos, a sua prática pode ter o efeito imprevisto de fortalecer elites locais que exercem o seu domínio mediante características culturais perversas, como o clientelismo e o patrimonialismo (Portes; Landoult, 2000, Ribot, 2007, Manor, 2004, Bursztyn, 1984). Os esforços de descentralização, bemsucedidos em diversas realidades, podem ser também negativos, quando se expressam em realidades em que a presença do poder público é tímida e até mesmo inexistente. Esse é o caso em áreas de fronteira de colonização (como em algumas partes da Amazônia). Ali a ausência do Estado abre espaço para o surgimento de poderes paralelos, privados, em certos casos legitimados pela força de seus protagonistas. Nesse caso, descentralização significa simplesmente uma renúncia à regulação pública do interesse público.

Outros aspectos, usualmente constantes no $\mathrm{MBG}$, refletem características originárias de um tipo cultural particular. O discurso da equidade de gênero, que emerge no Ocidente em um processo 
histórico próprio, sendo reconhecidamente um princípio básico da justiça social, pode gerar conflitos e instabilidades em sociedades organizadas culturalmente sob bases distintas das ocidentais. A busca da equidade de gênero pode não ter eco ou mesmo gerar conflitos, por exemplo, em ações relacionadas a alguns povos indígenas, pois tal discurso não necessariamente representa uma questão percebida por esses povos, além de ser externo à sua cosmologia. Existem casos em que relações materiais e simbólicas são barreiras para a implementação de alguns critérios do MBG. Assim, por exemplo, garantir canais formais de participação não significa, por si só, que esta se dê de forma igualitária, generalizada e eficaz (Cleaver, 2001, Kothari, 2001, Sayago, 2000). Como afirma Cleaver (2001, p. 53, tradução dos autores), “[uma] forte ênfase na participação dos indivíduos e em seu potencial de empoderamento não é sustentada por análises convincentes de posições individuais, de variabilidade dos custos e benefícios da participação, das oportunidades e restrições vivenciadas pelos potenciais participantes”.

Restrições econômicas ou sociais podem impedir que determinados indivíduos participem. Podem ocorrer, inclusive, situações em que o comparecimento e a ação nos fóruns de participação estabelecidos constituam monopólio daqueles que não sofrem tais restrições e que podem regularmente se locomover, prescindir de horas de trabalho e ter voz ativa nos canais. Essa situação acaba institucionalizando a exclusão, ao invés de estimular a participação (Manor, 2004, Cleaver, 2005, Fuks; Perissinotto, 2006).

A participação restrita a um grupo de privilegiados pode criar uma elite local ou fortalecer o poder daqueles que já constituem elites. Sendo assim, as metodologias participativas presentes no MBG têm o potencial de reforçar e reproduzir desigualdades se elas somente promoverem as vozes e valores daqueles que são mais articulados e facilmente acessíveis na comunidade (Hayward et al., 2004). 
Além disso, a participação de alguns membros da comunidade não representa automaticamente toda a comunidade (Eversole, 2003).

Olival et al. 2007, p. 1027, em seu trabalho sobre participação nos conselhos municipais de desenvolvimento rural sustentável no território Portal da Amazônia, percebem a elitização e a pouca eficácia dos conselhos na generalização da cultura participativa, por isso, deve-se "repensar o conceito dos conselhos como uma instituição caracterizada pela participação ampliada, uma vez que a existência dessas instituições não conseguiu superar a distinção entre uma minoria de cidadãos politicamente ativos e a maioria passiva”.

Manor (2004) acentua outro aspecto da questão: desigualdades situadas nas relações de poder locais podem contaminar e direcionar instâncias criadas visando a participação, como os comitês de usuários de recursos comuns. O exercício formal da participação, sem o combate às desigualdades que antecedem o mecanismo, faz com que tal abismo seja reproduzido nos comitês e que as decisões deles sejam tomadas por aqueles que, tradicionalmente, controlam o processo político local (Cleaver, 2005, Blair, 2000, Ribot, 2007, Wong, 2003, Milani, 2006).

Esse fenômeno é percebido em comitês de bacia hidrográfica, no Brasil, onde a simples determinação de que deve haver participação dos atores envolvidos não é garantia da representatividade dos participantes, nem da efetiva expressão dos interesses e visões de cada um (Pereira, 2008, Souza, 2008). Dino (2003), analisando o processo de formação do comitê da sub-bacia hidrográfica do rio Paracatu - criado tendo em vista que o Plano Diretor no município de Paracatu, no Estado de Minas Gerais, assim o determinava observa que a formação e o funcionamento dele foram pautados pelo clientelismo, tendo a participação se limitado às elites locais. Nesse caso, o comitê constituía, sobretudo, espaço de lutas políticas entre as elites dominantes, o que fez com que ampla parcela da população 
fosse excluída e não representada no processo. Nesse caso, o comitê, a despeito de sua finalidade formal, foi marcado pela cultura política tradicional e por relações clientelistas locais (Dino, 2003).

Em outra frente, Sayago (2007), aponta que os Conselhos Municipais de Desenvolvimento Rural foram criados apenas para atender às exigências legais do repasse de verbas públicas, em especial do Programa Nacional de Fortalecimento da Agricultura Familiar (Pronaf). Para a autora, esses conselhos apresentam baixa capacidade técnica e de formação, reduzida articulação com outras instâncias, além de um baixo nível de participação e de envolvimento dos atores sociais. Isso tudo faz com que o processo de descentralização, promovido com a criação do comitê, seja "não democrático, centralizador, e, em alguns casos, legitimador das relações de poder já existentes” (Sayago, 2007, p. 18).

Novamente, em seu estudo sobre o Portal da Amazônia, Olival et al. (2007, p. 1032) acentuam que "os conselhos muitas vezes são entendidos como instituições para legitimar decisões tomadas em outras instâncias”. De forma semelhante, podem ocorrer situações em que os reais beneficiários da política participam, mas de forma não autônoma, pois pode haver cooptação de lideranças dos grupos beneficiários e/ou manipulação de informações (Manor, 2004).

Analisando tentativas de estabelecer orçamentos participativos em cidades baianas, Milani percebe que o modus operandi local

... é predominantemente marcado por práticas clientelistas na intermediação das relações entre a sociedade e o governo local [...] isso significa, evidentemente, que os limites socioeconômicos, simbólicos e políticos funcionam como obstáculos relevantes à participação, podendo até mesmo aprofundar a desigualdade política no âmbito dos próprios dispositivos participativos. (Milani, 2006, p. 188-189)

O conceito de capital social é um tema-chave no MBG. Promover capital social significa adotar conjuntamente uma ampla 
gama de conceitos, tais como participação e empoderamento. Porém, existe uma clara imprecisão conceitual no caso do capital social (e de diversos outros componentes do MBG). Isso ocorre porque o conceito de capital social utilizado nas políticas ambientais e de desenvolvimento reflete o uso do conceito por alguns autores, notadamente Putnam (1990) e Coleman (1986). Para estes autores, o capital social representaria "características da organização social, como confiança, normas e sistemas, que contribuam para aumentar a eficiência da sociedade, facilitando as ações coordenadas" (Putnam, 1996, p.177). O capital social teria a finalidade de fortalecer a solidariedade comunitária através de expectativas de reciprocidade e aplicação das normas sociais (Portes, 1998). Outro ponto a ser enfatizado é que essa visão do conceito

refere-se a "redes sociais, normas e confiança", as quais contribuem para a criação de uma sociedade civil "vibrante" ou "robusta" porque elas facilitam a resolução dos problemas da ação coletiva [...] A idéia básica é que por meio da "participação” em “associações locais voluntárias", as pessoas são "empoderadas" na "sociedade civil” (Harriss, 2001, p. 25, tradução dos autores)

Essa visão do capital social permitiria o desenvolvimento de cooperação e confiança entre os indivíduos de um grupo social. Esse grupo se tornaria coeso e engajado na vida cívica. Tais elementos seriam propícios à melhora das condições de vida nos países subdesenvolvidos, diminuindo a pobreza e levando ao desenvolvimento e ao bem-estar. Como ingrediente vital para o desenvolvimento econômico ao redor do mundo, o capital social seria o elo perdido do desenvolvimento (Grootaert, 1998). Contudo, experiências práticas (que serão descritas na sequência) demonstram que existem incompletudes na abordagem do conceito de capital social nos moldes trabalhados por Putnam e Coleman.

A análise de Pierre Bourdieu sobre o conceito auxilia a preencher algumas lacunas na utilização do conceito em realidades 
concretas. Bourdieu lidou com o conceito de capital social desde a década de 1970 e desenvolveu um fundamento teórico que se presta a contextualizações de forma mais efetiva do que os usos dados ao mesmo termo em casos aplicados a realidades particulares (Portes, 1998). É possível dizer que, em geral, os autores que empregam o conceito convergem para a definição de Bourdieu de que o capital social é “a soma de recursos existentes ou potenciais ligados à posse de uma rede de relações duráveis ou de relações mais ou menos institucionalizadas de conhecidos ou reconhecimento mútuo” (Bourdieu, 1985, p. 248 apud Portes, 1998, p. 3, tradução dos autores). Entretanto, existem nuances conceituais entre as abordagens.

A diferença mais importante está relacionada à questão das relações de poder. Putnam (1996) assegura que é possível criar e fomentar capital social para que nasça uma comunidade cívica. Contudo, para Bourdieu, não é possível criar ou promover intencionalmente capital social, mas sim alocá-lo. Para que um grupo ou indivíduo aumente o seu quantum de capital social, outro ator perde influência ou legitimidade social. Isto ocorre porque a distribuição do capital social segue a lógica dos campos sociais (Bourdieu, 1990, 1998). Para este autor, os campos sociais seriam espaços de disputa, onde são travadas lutas concorrenciais entre atores em torno de interesses específicos. A distribuição do capital específico do campo determina quais são os atores dominantes e os dominados nesse campo. Sendo assim, pela dinâmica dos campos sociais, a concentração de capital social em torno de um indivíduo ou grupo - que ocuparia uma posição dominante - implica que outros atores serão privados da posse daquele capital, ou seja, ocupariam posições dominadas no campo.

Ocapital social seria, assim, recurso social por excelênciae pode ser mobilizado tanto para uma maior participação e empoderamento de um grupo quanto para aprofundar particularidades culturalmente arraigadas, de acordo com a dinâmica dos campos sociais vigente nas realidades específicas. Essa segunda possibilidade representa o 
lado perverso do capital social (Portes; Landoult, 2000). A base do poder de grupos como a Máfia ou de lideranças tradicionais, como os “coronéis” no sertão nordestino, não é outra senão o seu alto capital social.

Os estudos de Bebbington (2000) sobre os Andes e de Cleaver (2005) sobre a Tanzânia mostram que fomentar capital social em comunidades com graves desigualdades de poder ou de recursos materiais e simbólicos não contribui para melhorar a governança local, mas agrava os contextos de desigualdade, por obscurecer as relações de poder. Conforme acentua Harriss (2001, p. 31, tradução dos autores), “o conceito descontextualizado de capital social, que se tornou popular como uma panacéia do desenvolvimento, obscurece relações de poder e, por conseguinte, políticas”.

Os exemplos aqui citados, relacionados apenas a alguns preceitos entre os mais de 200 passíveis de serem encontrados no MBG, bastam para mostrar que o uso de certos critérios não é garantia de sua efetividade ou desejabilidade e esse uso pode ocorrer de forma acrítica e inocente. Isso ocorre porque a possibilidade de generalizar a adoção de certos critérios ou princípios é limitada. Analisando os gargalos relacionados aos contextos particulares, percebe-se que cada contexto deve priorizar características distintas. Ademais, alguns elementos, se promovidos em contextos específicos, não melhoram, mas prejudicam o processo de governança. Esse agravamento mostra como o MBG ajuda a obscurecer as relações de poder e as mazelas dos processos políticos particulares, fazendo com que a dimensão crítica de análise seja eclipsada. Além disso, o uso acrítico e inocente do MBG é território propício para a ação dos free-riders ou caronas do discurso.

\section{Da boa governança à governança viciosa}

O free-rider discursivo (aplicado à questão ambiental) é aquele ator que, ao manifestar apoio retórico ao desenvolvimento 
sustentável, desfruta dos benefícios de ser "ecologicamente correto" sem de fato sê-lo. Ou seja, ele se apropria e se beneficia dos bens simbólicos sem que esse apoio discursivo tenha respaldo na sua prática, que continua sendo guiada por interesses individuais/ imediatistas (Fonseca; Bursztyn, 2007). Quando um discurso atinge um forte grau de difusão e de aceitação pela sociedade, esta sociedade confere prestígio àqueles que o professam e praticam (Bourdieu, 1990, 1998). Ao mesmo tempo, lentamente são criados mecanismos de exclusão e estigmatização (Goffman, 1982) que atingem aqueles contrários aos discursos socialmente corretos. Isso permite que atores reproduzam determinado discurso e aparentem praticá-lo quando, na verdade, a sua prática cotidiana é guiada por interesses particulares que, muitas vezes, entram em choque com o discurso utilizado como instrumento de retórica.

Os caronas do discurso são pautados por uma dupla lógica: eles desfrutam das vantagens de serem identificados com um conjunto de ideais reconhecido como positivo, cujo discurso reproduzem e, ao mesmo tempo, estão isentos dos custos dos comportamentos diferenciados e das sanções ou mecanismos de exclusão relacionados à não-prática de tais comportamentos. Quanto mais geral, ambíguo e descontextualizado é o discurso (no caso, ambiental), maior a possibilidade de o mesmo ser alvo dos caronas. O caráter geral do MBG dá margem a que um ator venha a aderir de fato a apenas alguns de seus elementos internos, mas que a sua conduta seja percebida como se ele aderisse efetivamente a todos os critérios e princípios.

A ambigüidade do discurso favorece a percepção deformada de que um princípio está sendo utilizado adequadamente, quando a sua própria validade é posta continuamente em xeque pela realidade real (embora não pela realidade imaginada). A postura cega ao debate faz com que as virtuais deficiências do discurso sejam relegadas a um segundo plano e permite que as falhas sejam continuamente 
reproduzidas e aprofundadas. Já a descontextualização discursiva reflete a situação em que o fracasso no uso do princípio em distintas realidades particulares não implica questionamento do próprio princípio, pois as suas premissas continuam válidas e legitimadas pelos casos em que houve sucesso em seu uso.

O MBG é exemplo de discurso vulnerável à ação dos freeriders discursivos. Contando com tantos quesitos, é impossível que todos eles sejam contemplados e promovidos simultaneamente. Porém, a expressão real de alguns deles como “aquisições” positivas transmite a impressão de que todo o conjunto de critérios está sendo implementado igualmente.

Certos elementos internos ao discurso da boa governança são imprecisos conceitualmente e se sobrepõem uns aos outros, podendo abrir espaços para que se contradigam mutuamente. É o caso, por exemplo, do princípio da descentralização, promovido como um a priori, que pode ser tributário do fortalecimento indesejável de elites locais, contradizendo o critério da ampliação da democracia participativa. Contudo, a maneira superficial e acrítica como esses elementos são apresentados obscurece as ambigüidades e contradições internas.

A descontextualização está presente, pois na prática do MBG raramente a realidade local é estudada a fundo. As particularidades culturais, as relações de poder e os processos políticos característicos não constituem o lócus de onde emergem alternativas de ação. Contudo, devido à sua generalidade, não é possível culpar diretamente critérios como descentralização, capital social, ou qualquer outro, pelo fracasso na melhoria da governança. Esses critérios podem impactar e ser parte das ações direcionadas localmente, mas o sucesso ou fracasso das ações depende menos de itens únicos e mais da inter-relação dos elementos do próprio MBG com as particularidades locais. Quando o fracasso na implementação 
de um quesito do MBG se torna evidente, são propostas fórmulas teóricas e conceituais para repará-lo. Isso contribui para ampliar ainda mais o MBG, ao invés de simplificá-lo.

Conforme assinalado acima, a regra de seleção e financiamento de programas e projetos favorece aqueles que reproduzem, mesmo que só nas aparências, os princípios nele contidos. Sendo assim, elites locais, organizações não-governamentais, associações e grupos de interesses com finalidades reais distintas de sua posição retórica podem se beneficiar de apoios reais para a implementação de projetos e políticas socioambientais, o que implica riscos de desvirtuamentos ou baixa efetividade. O próprio fato de que $\mathrm{o}$ envolvimento de organizações não-governamentais seja um dos critérios estabelecidos no MBG faz com que elas se tornem parte integrante do processo. Porém, como critérios relacionados à representatividade das organizações e ao grau de interesse público ou compromisso real são de difícil aferição e não fazem parte dos itens do MBG, há amplo espaço para organizações free-riders.

Na realidade, a melhoria da efetividade dos princípios constantes no MBG não depende da quantidade de critérios, mas sim de sua pertinência e factibilidade. Portanto, não se trata de seguir agregando novos parâmetros, mas sim de criar filtros e critérios de adaptação. O gargalo fundamental está geralmente concentrado nas relações de poder e na desigualdade de recursos materiais e simbólicos locais.

Vale assinalar que os componentes da boa governança não são intrinsecamente negativos ou indesejáveis. Pelo contrário, cada um deles pode efetivamente contribuir para avanços. A questão é a profusão de quesitos e a falta de hierarquia de importância e premência entre eles. Além disso, é necessária uma real contextualização desses quesitos, identificando os que realmente são essenciais em determinado contexto, os que são apenas ideais e os 
que são suscetíveis de serem distorcidos e manipulados localmente, conforme cada realidade específica. A expressão da lógica dos freeriders, como corolário da fragilidade de processos decisórios que se fundamentam em fórmulas ideais genéricas, como o MBG, abre amplo espaço para que os recursos destinados ao desenvolvimento socioambiental local acabem servindo para fins opostos aos previstos, contribuindo para ampliar desigualdades e aprofundar situações de pobreza, exclusão e degradação ambiental.

O conceito de free-rider é proposto por Olson (1999) para explicar porque, na lógica da ação coletiva, não basta que os indivíduos sejam conscientes de seus próprios interesses e favoráveis à aquisição de benefícios coletivos para que eles se mobilizem em busca de tais benefícios. $\mathrm{O}$ autor assegura que, quanto maior for $\mathrm{o}$ grupo e mais geral for o benefício coletivo, menor é a possibilidade do benefício ser provido. Quando o grupo é grande e o benefício é demasiadamente geral, a ação de um único indivíduo tem reduzido impacto relativo, seja essa ação favorável ou contrária à aquisição do benefício coletivo. Ademais, em grupos grandes, o monitoramento da conduta particular é difícil e de elevado custo para os demais membros do grupo.

O free-rider é aquele que desfruta do bem coletivo eventualmente provido sem ter incorrido em qualquer custo para a sua obtenção. Isso ocorre seja porque a relação custo/benefício desestimula o ator a agir em prol de seus interesses, seja por ser impossível excluir o ator que não contribui com a ação do grupo dos beneficiários. No caso dos free-riders, é racional não cooperar na aquisição do benefício coletivo, mas ser beneficiário dos esforços alheios. Para Elster (1989), caso as instituições sociais vigentes não sejam capaz de direcionar e controlar as ações individuais, a racionalidade individual pode conduzir ao desastre coletivo, já que "a cooperação individual não é individualmente estável nem acessível: todos darão o primeiro passo para dela se afastar e ninguém dará o primeiro passo para dela se aproximar” (Elster, 1989, p. 188). 
Neste contexto, a busca por interesses individuais impede a obtenção do bem comum e leva, em alguns casos, a uma "tragédia dos bens comuns" (Hardin, 1968). Um exemplo para explicar essa tragédia pode ser assim exposto: em um lago, a sobre-exploração pela atividade pesqueira leva a uma diminuição no número de peixes disponíveis, gerando prejuízo para os pescadores. Eles, então, formam um grupo para a obtenção do bem comum (um estoque pesqueiro sustentável) e criam regras para a pesca no lago (controle do número e tamanho de peixes pescados, épocas proibidas para a pesca etc.). Com essas medidas, o número de peixes aumenta e o benefício coletivo começa a ser provido. Porém, um indivíduo isolado auferiria benefícios individualmente se não respeitasse as regras e se não arcasse com os custos do grupo, pois, nesse caso, "há grandes vantagens em não cooperar, exatamente porque os demais assumem comportamentos cooperativos” (Lima; Rua, 2003, p. 78). Ele "pegaria carona” no benefício coletivo, pois ninguém poderia excluí-lo de ser beneficiado com um aumento do estoque de peixes. Ao mesmo tempo, a sobre-pesca praticada por esse indivíduo isolado não terá grande impacto no estoque do lago.

Essas condições podem levar à situação em que ninguém queira pagar espontaneamente os custos da ação do grupo, mas que todos possam se beneficiar das vantagens derivadas do comportamento alheio. É sob tais condições que pode ocorrer a "tragédia", representada pela sobrepesca e pelo conseqüente esgotamento do estoque pesqueiro do lago. O free-rider, por desfrutar do bem coletivo sem pagar os custos dele, é o principal fator que tende a impedir que os grupos grandes atinjam os seus objetivos.

Quando o comportamento do carona ocorre no âmbito da expressão formal da adesão a uma idéia, a diferença entre a posição retórica dos indivíduos e a sua prática efetiva constitui o modelo de ação dos free-riders discursivos. De forma semelhante ao conceito original, a ampla ação dos caronas do discurso pode levar a uma 
tragédia coletiva, em que o fingir agir obscurece o agir efetivamente conforme o discurso. A promoção acrítica e fechada do MBG pode contribuir para a promoção dessa tragédia.

Em algum momento foi preciso atribuir um adjetivo (boa) ao conceito de governança, para melhor qualificá-lo, diferenciando-o da governança sem qualificativo. Agora, é relevante esclarecer que nem todos os casos que se habilitam ao enquadramento na boa governança, por atenderem aos critérios do MBG, são valorativamente positivos. Quando a boa governança apresenta falhas estruturais e é desviada de seus fins originais, ao mesmo tempo em que a ação dos freeriders discursivos é regra e não exceção, é preciso apelar para a denominação governança viciosa. Esta pode ser encontrada em circunstâncias em que "vários dos atributos da boa governança são formalmente inscritos em ações de interesse público, mas sua prática revela desvirtuamentos” (Bursztyn, 2009).

\section{A governança suficientemente boa}

Para enfrentar as falhas da governança viciosa e diminuir o número de caronas do discurso, é necessário que o escopo do que seja um MBG seja redefinido. Grindle $(2004,2007)$ propõe a alteração do referencial da boa governança para o referencial de uma noção de governança suficientemente boa. Esta reflete uma condição minimamente aceitável de desempenho do governo e da sociedade civil, na qual não existem características pré-determinadas para que o processo de governança seja efetuado. Cada país ou localidade teria os seus próprios constrangimentos e oportunidades. Isso exige que as estratégias de governança surjam a partir de contextos particulares. A referida autora afirma que estratégias bem-sucedidas de governança são fruto de processos históricos particulares. Não há como implementar uma ampla lista de "boas práticas” simultaneamente, seja porque algumas não são aplicáveis em certos contextos, seja 
porque certas características devem existir previamente para que outras possam ser adequadamente implementadas.

É fundamental definir em cada contexto quais características são realmente necessárias, quais são apenas ideais, e quais são inviáveis. Esse esforço de definição implica o conhecimento das realidades locais, de sua cultura, de seu meio biofísico, de suas relações de poder, de suas arenas políticas e de suas estruturas previamente existentes.

Após essa definição, é possível elaborar estratégias com foco na promoção das características essenciais e que sejam viáveis em sua implementação, obedecendo a uma hierarquia no tempo e entre prioridades. O esforço de definição permite também a identificação de gargalos locais que podem impedir ou distorcer ações futuras. Deve-se, então, garantir condições prévias para as ações posteriores, enfrentando tais gargalos em um momento anterior à adoção de alguma política ou estratégia, ou modificando a própria estratégia de ação.

Para que esta última seja localmente sensível, é necessário que os planejadores e gestores de programas e projetos sejam permeáveis a alternativas locais que favoreçam uma melhor governança local. Contudo, tal permeabilidade não deve ser confundida com o imperativo de ações unilaterais, como impor o surgimento de processos participativos locais como condição para atender a um quesito do MBG. Provocar ou forçar grupos sociais a expressar vontades que nem sempre lhes são claras e perceptíveis é inverter a lógica, pois "a idéia de construir de baixo para cima as propostas de ação pode se materializar de forma impositiva, de cima para baixo” (Bursztyn, 2009).

Duas características são cruciais para a governança suficientemente boa: a percepção do processo histórico e o foco nas relações de poder. Grindle (2004) afirma que nos países 
desenvolvidos diversos elementos só foram adquiridos porque pré-existiam outros que lhes ofereceram suporte para emergir. Os exemplos anteriores deste artigo, relacionados com a participação e com a descentralização, demonstram que, para implementar adequadamente as boas práticas constantes no MBG, o contexto local (em suas múltiplas variáveis) deve ser permissivo àquelas intervenções específicas de governança.

Por outro lado, existem diversos casos em que foram alcançados progressos, no tocante ao desenvolvimento de países subdesenvolvidos, na presença de características relacionadas à "má governança” e em período de tempo anterior às tentativas de implementação das boas práticas listadas no MBG. A China e o Vietnam, por exemplo, mesmo sob diversas características consideradas negativas do ponto de vista da boa governança, obtiveram avanços no campo do desenvolvimento econômico e da redução da pobreza (Quiam, 2003, Chang, 2002 apud Grindle, 2007). Da mesma maneira, a simples iniciativa de informar a população do nordeste brasileiro sobre os seus direitos, sem que isso implicasse grandes mudanças qualitativas de governança, desencadeou uma significativa melhora na provisão de serviços básicos (Tendler, 1998).

A eficácia da governança é, nesse sentido, fruto de um processo histórico. Tal processo é impactado pelas relações de poder, que favorecem a emergência de alguns elementos e constituem obstáculos para outros. Promover características sem conhecer e priorizar os possíveis impactos da distribuição de recursos e poder é um largo passo rumo ao fracasso da iniciativa.

\section{Considerações Finais}

O termo governança, associado à esfera púbica, implica ir além do governo na regulação e incluir diversos setores e grupos 
na elaboração e implementação de ações direcionadas ao interesse coletivo. A inclusão dos diversos atores sociais favorece, em tese, uma gestão democrática e pluralista, que permita compatibilizar interesses diversos. Esse texto explorou a idéia de que, mesmo sendo desejável tal inclusão, ela deve ser feita de acordo com cada contexto local.

A idéia de promover a boa governança assumiu o status de "mantra" para as agências doadoras, para os países ricos e para os responsáveis pela execução das políticas ambientais e de desenvolvimento (Grindle, 2007; Nanda, 2006). Contudo, tal idéia segue um modelo particular de difusão, reprodução e ampliação que, ao procurar incluir todos os critérios desejáveis para uma boa governança, propicia a inviabilidade na promoção simultânea dos critérios da boa governança, abrindo espaço para a ação dos caronas do discurso e para a banalização no uso discursivo e na implementação dos conceitos e critérios do MBG.

A governança não deve estar fundada na adoção de critérios genéricos definidos num MBG. Deve, sim, obedecer a um conjunto reduzido e flexível de princípios, definidos caso a caso, para que haja identificação entre o contex to e a agenda, permitindo uma governança mais eficaz. Simultaneamente, deve ser alterada a maneira como se efetuam a seleção e o financiamento de programas e projetos. É falaciosa a idéia de que quanto mais itens da boa governança houver, melhor e mais sustentável é o projeto. Reproduzir o discurso da boa governança e da sustentabilidade não garante que o discurso tenha efeitos na prática e, se o tiver, que essa prática ocorra de forma isenta e imparcial.

A cultura burocrática atual, quebusca associar a boa governança ao cumprimento de uma lista extensa de critérios necessários, favorece a dinâmica dos free-riders discursivos e contribui para o aumento do fosso entre o discurso e a prática na questão ambiental. 
Assim, na tentativa de se obter uma boa governança, pode-se chegar a uma governança viciosa. A idéia de governança suficientemente boa representa uma alternativa a este dilema, diminuindo o número de free-riders e contextualizando a questão da governança. Ao incorporar relações de poder e focar o contexto local, com uma definição ad hoc de essencialidades, a governança suficientemente boa pode ser uma chave para reverter frustrações verificadas nos processos de governança.

\section{The banalization of sustainability: reflections on environmental} governance in a local scale

Abstract: The process of making decisions and implementing environmental policies tends to adopt internationally accepted criteria as requisites of viability and sufficiency to attain aimed ends. It is as if there was a handbook of general rules for the attainment of sustainable development. Currently there is a kind of a (virtual) "good governance manual" or "handbook", wich serves as a guide and a requisite for the drafting of socioenviromental programs and projects. However, the indiscriminate reproduction and the endless expansion of the list of requirements may have an effect that is contrary to what is expected of them, helping to create obstacles to the efficient implementation of environmental and development policies. The concern about the formal compliance with general criteria may hinder their substantive expression. This allows space for free-riders of the environmental discourse and for the creation of a void between discourse and practice in the field of environmental management. This article examines how these requisites for good governance are produced and reproduced. The dynamics of this process, governed by the aformentioned handbook, help make those requisites trite and volatile. If sustainability is transformed into a trite matter, there is a growing distance between the politically correct discourse and the practical effectiveness of environmental and developmental policies. In order to reduce this distance, this text proposes the use of the concept of sufficiently good governance. This concept may represent an alternative to the failings of the 
handbook, as it helps focus on the essential aspects and separate the intended from the possible and from the indispensable.

Key words: good governance; environmental governance; free-riders; participation; social capital; decentralization; empowerment.

\section{Referências}

BANCO MUNDIAL. Governance and development. Washington, DC: The World Bank, 1992.

BEBBINGTON, Anthony. Reencountering development: livelihood transitions and place transformation in the Andes. Annals of the Association of American Geographers, v. 90, p. 495-520, 2000.

. Social capital and development studies 1: critique, debate, progress? Progress in Development Studies, v.4, n. 4, p. 343-349, 2004.

. Social capital and development studies II: can Bourdieu travel to policy? Progress in Development Studies, v. 7, n. 2, p. 155-162, 2007.

BLAIR, Harry. Participation and accountability at the periphery: democratic local governance in six countries. World Development, v. 28, n. 1, p. 21-39, 2000.

BOURDIEU, Pierre. Coisas ditas. São Paulo: Brasiliense, 1990.

. O poder simbólico. Rio de Janeiro: Bertrand Brasil, 1998.

BURSZTYN, Marcel. O poder dos donos: planejamento e clientelismo no Nordeste. Petrópolis: Vozes, 1984.

. Think locally, act globally: new challenges to environmental governance. Cambridge: Harvard University, 2009. (CID Working Paper, n. 33).

CLEAVER, Frances. Institutions, agency and the limitations of participatory approaches to development. In: COOKE, B; KOTHARI, U. (Orgs.). Participation: the new tyranny?. New York: Zed Books, 2001. 
CLEAVER, Frances. The inequality of social capital and the reproduction of chronic poverty. World Development, v. 33, n. 6, p. 893-906, 2005.

COLEMAN, James. Social capital in the creation of human capital. American Journal of Sociology, v. 94, p. 95-120, 1988.

DINO, Karina Jorge. Cultura política local como dimensão da sustentabilidade na gestão de recursos hídricos: o caso do Comitê da Sub-Bacia Hidrográfica Mineira do Rio Paracatu. 2003. Dissertação (Mestrado) - Universidade de Brasília, 2003.

DRAKE, Elisabeth et al. Good governance and the World Bank. University of Oxford, 2002. Disponível em: <http://www.reformwatch.net/ fitxers/110.pdf $>$. Acessado em: 9 jan. 2009.

ELSTER, Jon. Marxismo, funcionalismo e teoria dos jogos. Lua Nova, n. 17, p. 163-204, 1989.

EVERSOLE, Robyn. Managing the pitfalls of participatory development: some insight from Australia. World Development, v. 31, n. 5, p. 781-795, 2003.

FINE, Ben. The developmental State is dead: long live social capital? Development and Change, v. 30, p. 1-19, 1999.

FONSECA, Igor; BURSZTYN, Marcel. Mercadores de moralidade: a retórica ambientalista e a prática do desenvolvimento sustentável. Ambiente e Sociedade, v. 10, n. 2, p. 169-186, 2007.

FUKS, Mario; PERISSINOTTO, Renato. Recursos, decisão e poder: Conselhos Gestores de Políticas Públicas de Curitiba. Revista Brasileira de Ciências Sociais, v. 21, n. 60, p. 67-81, 2006.

GOFFMAN, Erving. Estigma: notas sobre a manipulação da identidade deteriorada. 4. ed. Rio de Janeiro: Zahar, 1982.

GRINDLE, Merilee. Good enough governance revisited. Development Policy Review, v. 25, n. 5, p. 553-574, 2007. 
GRINDLE, Merilee. Good enough governance: poverty reduction and reform in developing countries. Governance: An International Journal of Policy, Administration, and Institutions, v. 17, n. 4, p. 525-548, 2004.

GROOTAERT, Christiaan. Social capital: the missing link? SCI working paper, n. 3, 1998. Disponível em: <http://povlibrary.worldbank.org/ files/5459_sciwp3.pdf $>$. Acessado em: 5 mar. 2009.

HARDIN, Garrett. The tragedy of the commons. Science, v. 162, p. 12431248, 1968.

HARRISS, John. Public action and the dialectics of decentralisation: against the myth of social capital and the missing link in development. Social Scientist, v. 29, p. 25-40, 2001.

HAYWARD, Chris; SIMPSON, Lyn; WOOD, Leanne. Still left out in the cold: problematising participatory research and development. Sociologia Ruralis, v. 44, n. 1, p. 95-108, 2004.

KOTHARI, Uma. The case for participation as tyranny. In: COOKE, B.; KOTHARI. U. (Orgs.). Participation: the new tyranny? New York: Zed Books, 2001.

LIMA, Ricardo Barbosa; RUA, Maria das Graças. Cotidiano, racionalidade e sereias: o dilema do prisioneiro como metáfora da questão ambiental. Sociedade e Estado, Brasília, v.18, n. 1/2, p. 67-88, 2003.

MANOR, James. User committees: a potentially damaging second wave of descentralization? The European Journal of Development Research, v. 16, n. 1, p. 192-213, 2004.

MCFARLAND, Andrew. Neopluralism. Annual Review of Political Science, v. 10, p. 45-66, 2007.

MILANI, Carlos. Políticas públicas locais e participação na bahia: o dilema gestão versus política. Sociologias, v. 8, n. 16, p. 180-214, 2006.

NANDA, Ved. The good governance concept revisited. The Annals of the American Academy of Political and Social Science, n. 603, p. 269283, 2006. 
OLIVAL, Alexandre; SPEXOTO, Andrezza; RODRIGUES, José. Participação e Cultura política: os Conselhos Municipais de Desenvolvimento Rural Sustentável no Território Portal da Amazônia. RER, Revista de Sociologia e Economia Rural, v. 45, n. 4, p. 1013-1035, out./dez. 2007.

OLSON, Mancur. A lógica da ação coletiva: os benefícios públicos e uma teoria dos grupos sociais. São Paulo: Edusp, 1999.

PEREIRA, Maria do Carmo. Composição do Comitê da Bacia Hidrográfica do Rio Paraguassu: análise da origem geográfica e do setor econômico representado por seus membros como fatores intervenientes na gestão participativa de recursos hídricos. 2008. Dissertação (Mestrado) - Universidade de Brasília, 2008.

PORTES, Alejandro. Social capital: its origins and applications in modern Sociology. Annual Review of Sociology. v. 24, p. 1-24, 1998.

PORTES, Alejandro; LANDOLT, Patrícia. Social capital: promise and pitfalls of its role in development. Journal of Latin American Studies, v. 32, p. 529-547, 2000.

PUTNAM, Robert. Comunidade e democracia: a experiência da Itália moderna. Rio de Janeiro: Editora Fundação Getúlio Vargas, 1996.

RIBOT, Jesse. Representation, citizenship and the public domain in democratic decentralization. Society for International Development, v. 50, n. 1, p. 43-49, 2007.

SANTISO, Carlos. Good governance and aid effectiveness: The World Bank and conditionality. The Georgetown Public Policy Review, v. 7, n. 1, p. 1-22, 2001.

SAYAGO, Doris. A invenção burocrática da participação: discursos e práticas no Ceará. 2000. Tese (Doutorado) - Universidade de Brasília, 2000.

. Os Conselhos de Desenvolvimento Territorial: entre a participação e a representação. Revista Brasileira de Gestão e Desenvolvimento Regional, v.3, n. 4, p. 9-21, 2007. 
SOUZA, Larissa Cayres. Desafios da implementação da Política Nacional de Recursos Hídricos: o caso da Bacia do São Francisco. 2008. Dissertação (Mestrado) - Universidade de Brasília, 2008.

TENDLER, Judith. Bom governo nos trópicos: uma visão crítica. Rio de Janeiro: Revan, 1998.

UNITED NATIONS. ECONOMIC AND SOCIAL COMISSION FOR ASIA AND THE PACIFIC (Unescap). What is Good Governance? [s.d.] Disponível em: http://www.unescap.org/pdd/ prs/ProjectActivities/Ongoing/gg/governance.asp >. Acessado em: 9 jan. 2009.

WONG, Kwok-Fu. Empowerment as a panacea for poverty: old wines in new bottles? Reflections on the World Bank's conception of power. Progress in Development Studies, v. 3, n. 4, p. 307-322, 2003. 